\title{
'A new 'new' Mental Health Act? Reflections on the proposed amendments to the Mental Health Act 1983
}

\section{N Glover-Thomas}

The Liverpool Law School, University of Liverpool, Liverpool, UK Email: nglover@liv.ac.uk

\begin{abstract}
Since 1998, several attempts have been made to reform the existing mental health legislation - the Mental Health Act 1998. However, all efforts thus far have been resoundingly rejected by mental health charities, psychiatrists and related professions. Following the Government's decision to abandon the draft Mental Health Bill in March 2006, plans to introduce new legislation designed to amend the existing 1983 Act have been published. This shorter bill is expected to be introduced before Parliament in October 2006. The amendments will focus on six key policy areas including supervised community treatment, the nearest relative, the definition of mental disorder and detention criteria. It is also intended that the Mental Capacity Act 2005 will be amended to bridge the present 'Bournewood' gap.
\end{abstract}

\section{Introduction}

After an 8 year campaign by mental health charities, including the 60-organization strong Mental Health Alliance, psychiatrists and related professions, the publication of the White Paper Reforming the Mental Health Act in 2000 and two controversial draft bills in 2002 and 2004, the draft Mental Health Bill was finally abandoned in March 2006. Instead, the Government plans to introduce new 'shorter, streamlined' legislation which amends the existing Mental Health Act (MHA) 1983. ${ }^{1}$ This shorter bill is expected to be introduced before Parliament in October 2006. It has been suggested that the 2004 Bill was finally dropped because of its unwieldy nature making it unlikely that Parliamentary time would ever be found. However, it is now a matter of record within psychiatric and associated care and support circles, that it was heavily opposed for several reasons including the contentious change to the 'treatability' criterion which campaigners argued would turn them into gaolers. ${ }^{2}$ The Government has argued that the proposed amending Bill will enable mental health legislation to reflect the continuing intention to modernize psychiatric services. It will also acknowledge that modern psychiatric practices have moved towards less restrictive community treatment and support. The intended amendments focus on six key policy areas:

- Supervised community treatment

- Professional roles

- Nearest relative

- Definition of mental disorder

Nicola Glover-Thomas is a Reader in Law, University of Liverpool. LL.B (Hons) (1995) from the University of Wales, College Cardiff and PhD (1998) from the University of Manchester. Her research interests lie in the field of Mental Health Law, including recent empirical research into the relationship between housing, mental health and charitable involvement.
- Criteria for detention

- Mental health review tribunals

The Government will also seek to amend the Mental Capacity Act (MCA) 2005 to reflect new proposals to bridge the 'Bournewood' gap.

\section{Supervised community treatment (SCT)}

\section{Proposed}

The Government intends to introduce SCT for patients following a period of detention in hospital. For a small number of patients, this will allow for them to live within the community whilst being subject to the MHA 1983. It is expected that this provision will be used most commonly for individuals with a history of discontinuing treatment after discharge. In the past, the so-called 'revolving-door' patient has presented significant concerns to both psychiatric service providers and those caring for individuals within the community. Such individuals tend to respond well to treatment while in hospital, are discharged into the community where they discontinue their treatment and experience deterioration in health, which often results in a further period of in-patient hospital care. It is envisaged that SCT will be of most benefit to individuals with chronic mental disorders and for whom the ability to manage their condition in a less restrictive environment presents challenges. Only people who would be a risk to their own health or safety or that of others if they did not continue to receive treatment when discharged will be considered for SCT. SCT will only be available to those who have first been assessed and treated in hospital and the clinical supervisor will have to decide whether SCT is an appropriate response to current need. The clinical supervisor must obtain a second medical opinion from the Approved Mental Health Professional (AMPH) before a patient can be placed on SCT. Certain requirements may be made of the patient in the commu- 
nity including the maintenance of regular contact with mental health services; however, where a patient refuses to consent to treatment while in the community treatment will not be forced upon them; instead they will be recalled to hospital. Renewal, review and discharge from SCT will be the same as for detention in hospital under section 3 of the 1983 Act (at 6 months, 1 year and then at yearly intervals, respectively) and safeguards for patients will exist with nearest relative rights and any treatment will be subject to second medical opinion after 3 months.

\section{Professional roles}

Who may take on the role of the approved social worker (ASW) and responsible medical officer (RMO) in the MHA 1983 will be broadened under current plans, thereby allowing persons with the right skills and experience to carry out key tasks.

\section{Current}

ASWs undertake several key roles under the 1983 Act including the making of admission applications for assessment, treatment and guardianship orders. RMOs are normally consultant psychiatrists and are usually section 12 approved indicating that they have special knowledge and experience in the diagnosis and/or treatment of mental disorder. They are responsible for a patient's treatment and decide when leave or discharge may be considered.

\section{Proposed}

The Government proposes to extend these roles to a wider group of appropriately trained and qualified mental health professionals creating the AMHP and the clinical supervisor role. Appropriate training and approval will be required of both roles.

\section{Nearest relatives}

\section{Current}

Under the MHA 1983 the nearest relative is a relative within a specified hierarchy of named relatives. At the top of the hierarchy is the spouse, followed by a relative with whom the patient lives or who provides substantial care to the patient. The nearest relative must be over 18 and, although she cannot refuse the title of nearest relative, she is under no obligation to exercise any of the powers given to the role. A nearest relative can delegate the role to another and, in some circumstances, the county court can transfer the nearest relative functions to another. The nearest relative has the power to discharge the patient from compulsory detention, to apply for or block detention, to request a review of the patient's detention and to receive information about the patient. It is possible for a patient to be assigned a nearest relative who could pose a risk to their health or well-being. At present, only a relative of the patient, an ASW or someone living with the patient can apply to the county court to displace a nearest relative and only then if she is too ill to act or is using her powers in an unreasonable fashion. Additionally, no account is taken of the Civil Partnership Act 2005, thus civil partners are not on an equal footing with spouses.

\section{Proposed}

Under the new proposals, patients themselves will be allowed to apply to the county court for the displacement of their nearest relative. A new basis for displacing a nearest relative will be introduced which effectively enables the displacement of an abusive or neglectful nearest relative. A patient, an AMPH, any relative of the patient and anyone living with the patient will be able to apply to the county court where it is reasonable that the person should not be able to act as the nearest relative. The county court when making an order will now be able to do so for an indefinite period. These proposed changes will also be applicable to those patients who are under SCT.

\section{Definition of mental disorder}

\section{Current}

Section 1 of the 1983 Act contains a general definition of mental disorder: 'mental illness, arrested or incomplete development of mind, psychopathic disorder and any other disorder or disability of mind'. Four specific categories of mental disorder are then described: mental illness, severe mental impairment, mental impairment, psychopathic disorder. Exclusions to the definition are also listed including immoral conduct, drug and alcohol dependency.

\section{Proposed}

The Government intends to simplify this definition so that it applies throughout the Act. The four separate categories of mental disorder will be abolished as, in the past, these have prevented some individuals from being detained and compulsorily treated. The removal of these categories may mean that some people who cannot now be brought under compulsion could be in the future, including those diagnosed with a personality disorder. A new provision will be included dealing specifically with learning disabilities. Learning disabilities will only be treated as a mental disorder for the purposes of the Act when it is associated with abnormally aggressive or seriously irresponsible conduct on the part of the person concerned.

The use of compulsion will be used in the future, as now, when the needs and risks associated with a patient make it appropriate rather than simply on the basis of a diagnostic label. The current exclusions within the MHA 1983 will be removed - it is now clearly recognized that immoral conduct and promiscuity are irrelevant to any definition of mental disorder. There are also no plans to include any more exclusions such as religious and political beliefs. The exclusion for sexual deviancy will also be removed because this has resulted in some patients who require compulsory care not receiving it because the disorder exhibits sexually deviant behaviour. The drug and alcohol dependency exclusion will be retained although reworded - merely being a drug addict or an alcoholic is not enough to be compulsorily detained. However, for many with mental disorders a dependency of some kind is also common. Where a dual diagnosis is indicated this will not prevent use of the legislation. 


\section{Criteria for detention}

\section{Current}

Civil criteria to detain are separated into two - detention to assess under section 2 and detention to treat under section 3 of the 1983 Act. Assessment may take place for 28 days if an individual is suffering from a mental disorder which warrants detention and is necessary for the individual's own health or safety or the safety of others. Detention for treatment may take place initially for 6 months where an individual is suffering from one of the four specific categories of mental disorder which makes it appropriate for medical treatment in hospital to take place, for those with a psychopathic disorder or mental impairment, treatment is likely to alleviate or prevent a deterioration in the condition, and treatment is necessary for the health or safety of the individual or of others.

\section{Proposed}

As with the definition of mental disorder the Government proposes to simplify the process by introducing a new, appropriate treatment test which will apply to all longerterm powers of detention. The appropriate treatment test will require consideration of both clinical and associated factors, including whether treatment in hospital is culturally appropriate and what impact hospitalization may have on the patient and her ability to maintain contact with the family. The appropriate treatment test is said to strengthen the detention criteria by ensuring that:

- ... [p]ractitioners are required by law to consider an holistic assessment of whether appropriate treatment is available before detaining someone, and

- clinicians have to decide what is clinically appropriate in the same way as for any other patient.

It is intended that the appropriate treatment test will apply to all patients equally irrespective of diagnosis, as focus will be placed upon the needs of patients and the risk that is posed by the disorder.

The fundamental revision which arises from proposed changes to the detention criteria is the removal of the 'treatability test' as it is customarily known. This test has traditionally been used to ensure only those individuals who could benefit from treatment would be compulsorily detained under the 1983 Act, i.e. that there was a clinical purpose to detention. The Government views the treatability test as being counter to both the wider public's interests and those of mentally disordered individuals. In the past some patients have been labelled 'untreatable' and have, therefore, been denied treatment and care within the Act, most notably those with severe personality disorders. It is argued that the treatability test focuses too much on the potential outcome of treatment rather than the beneficial aspects of the treatment process as a whole. The holistic approach adopted by the proposed appropriate treatment test is intended to respond to these difficulties.

Much of the basic legislative structure within the 1983 Act will remain unchanged. It is hoped that this will enable the transition and incorporation of these amendments to be relatively straightforward while enabling practitioners to work with essentially familiar legal frameworks. Six aspects of the legislation will continue:
- Practitioners will still have discretion about whether to apply for an individual's detention and guardianship (including renewal of both)

- Mental Health Review Tribunals (MHRTs) will still have discretion to discharge patients

- Detention for assessment under section 2 will continue for 28 days as the appropriate treatment test will not apply

- Guardianship under section 7 (providing for guardianship under the auspices of a local social services authority (or a named individual)) and section 37 (where a court can make a guardianship order) will remain unchanged except that they will apply to all types of mental disorder

- Nearest relatives will continue to have the same rights to discharge civil patients as they have now

- The test for whether treatment is necessary for the health or safety of the patient or for the protection of others remains the same.

\section{MHRTs}

\section{Current}

MHRTs provide an independent judicial forum which considers whether a patient should continue to be compulsorily detained under the MHA 1983. Patients have a right to apply to the MHRT and this right will not change following the new proposals.

\section{Proposed}

What the Government is seeking to do is increase the speed and frequency by which the MHRT system is involved in an individual's mental health service experience. It is suggested that this objective may be achieved through several routes including the reduction of time before hospital managers must refer patients to a tribunal, breaking the link between renewal of detention and referral to a tribunal and providing access to the tribunal to patients under SCT.

Several concerns in relation to the viability of these plans exist, most notably whether the tribunal system has a sufficient workforce and resources to accommodate the increasing demands on the system that these proposals would undoubtedly make. Several initiatives are being developed to respond to these potential problems including the use of judicial case management, electronic transfer of information and the setting up of a prospective booking system for hearings.

\section{Amendment of the MCA 2005: the 'Bournewood' proposals}

\section{Proposed}

In addition to the planned amendments to the MHA 1983, the Government also intends to close the 'Bournewood' gap by amending the MCA 2005. The 'Bournewood' gap arises when individuals who suffer from a disorder or disability of the mind, such as dementia, lack the mental capacity to consent to care and treatment. Some members of this vulnerable group may need to be deprived of their liberty for treatment or care. It is intended that the Bournewood proposals will provide legal safeguards to these 
individuals when they need to be deprived of their liberty, are unable to consent to care or treatment but are not, and could not, be detained under the MHA 1983. The proposals will cover individuals in hospital and people living in care homes registered under the Care Standards Act 2000. An individual must suffer from: (i) a disorder or disability of mind; (ii) lack the capacity to give informed consent to any care or treatment arrangements; and (iii) such care is considered to be in the individual's best interests following an independent assessment.

The proposals will only be used for people who meet the above criteria. Where an individual objects to proposed care or treatment, she will be dealt with in the same way as a capacitated individual refusing care. ${ }^{4}$ Therefore, the bulk of the expected 'Bournewood' group will be those with significant long-term learning disabilities and dementia. Where a hospital or care home identifies an individual as being deprived or likely to be deprived of her liberty, they must apply to the supervisory body (for a hospital, it will be the Primary Care Trust and for a care home, the local authority) for authorization of deprivation of liberty. Following receipt of a request for authorization of deprivation of liberty they must obtain assessments to establish whether the individual is (i) over 18, (ii) suffering from a disorder or disability of mind, and (iii) lacks capacity in relation to the question of whether or not she should be resident in the hospital or care home. Deprivation of liberty must also be shown to be in the individual's best interests in that consideration is given to relevant factors such as the individual's views and wishes, ${ }^{5}$ be necessary to prevent harm to him or her and a proportionate response to the need. Once an authorization is made it can last for a maximum of 12 months and the supervisory body will appoint a representative for the individual during the term of the authorization. Review of the authorization may occur if the hospital or care home requests a review or if the individual or her representative seeks it.

\section{Concluding comments}

Mental health law will always embody some acute con- flicts. After all, at the very heart of this field is the recognition that legal authority may be given to remove an individual's liberty because of a mental disorder rather than because of their conduct. It is therefore imperative that efforts are made to ensure that the law governing the decision-making processes are as clear as possible. The new streamlined proposals as outlined above still await a detailed response from campaigners and other interested parties, but several of the controversial plans remain present within the new proposals, leaving little doubt that there will be some objections. What is perhaps of greatest concern is the Government's stated 'implementation' plans which were published in June $2006 .{ }^{6}$ The focus of these plans give a feeling of urgency which may do little to assuage the view that both patients and those providing the care and treatment will suffer if insufficient time is given to consider the proposals more fully. The new draft Bill is expected to be introduced in October 2006 and the feasibility of how these proposals will work in practice, including the issue of how staff will be trained, changes to the Code of Practice and the development of advocacy programmes to name but a few, remain subject to some speculation.

\section{References}

1 Written Ministerial Statement, 23 March 2006: Minister of State, Department of Health, Ms Rosie Winterton.

2 The Royal College of Psychiatrists. Evidence Submitted to the Joint Committee on the Draft Mental Health Bill: http://www.rcpsych. ac.uk/pdf/MHB_draft04.pdf

3 Department of Health, The Mental Health Bill - Plans to Amend the Mental Health Act 1983: Briefing Sheet - Criteria - A2 (April 2006) Gateway ref: 6420, p 2: http://www.dh.gov.uk

4 That is, her competent refusal must be respected: Re MB [1997] 2 FLR 426, CA.

5 Section 4 Mental Capacity Act 2005. For a discussion of the Act generally see Sheather J. The Mental Capacity Act 2005. Clinical Ethics 2006; 1: 33-6.

6 Department of Health. The Mental Health Bill - Plans to Amend the Mental Health Act 1983: Briefing Sheet - Implementation - A8 (June 2006) Gateway ref: 6420: http://www.dh.gov.uk

\section{CE 07-008 Glover Author queries}

1. Please provide full author affiliation. 